\title{
WET DEPOSITION OF MERCURY AND AMBIENT MERCURY CONCENTRATIONS AT A SITE IN THE LAKE CHAMPLAIN BASIN
}

\author{
J. BURKE, M. HOYER, G. KEELER* ${ }^{*}$ T. SCHERBATSKOY ${ }^{1}$ \\ The University of Michigan Air Quality Laboratory, Ann Arbor, MI 48109-2029 \\ ${ }^{1}$ University of Vermont School of Natural Resources, Burlington, VT 05405-0088 \\ *Author to whom correspondence should be addressed
}

\begin{abstract}
The "Great Waters" program, established in the 1990 Clean Air Act Amendments, mandated that atmospheric deposition of hazardous air pollutants to Lake Champlain (including $\mathrm{Hg}$ ) be assessed. An assessment of the magnitude and seasonal variation of atmospheric $\mathrm{Hg}$ deposition in the Lake Champlain basin was initiated in December 1992 with one year of event precipitation collection, as well as collection of vapor and particle phase $\mathrm{Hg}$ in ambient air. Samples were collected at the Vermont Monitoring Cooperative air monitoring site at the Proctor Maple Research Center in Underhill Center, VT. The average volume-weighted concentration for $\mathrm{Hg}$ in precipitation was $8.3 \mathrm{ng} / \mathrm{L}$ for the sampling year and the average amount of $\mathrm{Hg}$ deposited with each precipitation event was $0.069 \mu \mathrm{g} / \mathrm{m}^{2}$. The total amount of $\mathrm{Hg}$ deposited through precipitation during 1993 was $9.26 \mu \mathrm{g} / \mathrm{m}^{2} / \mathrm{yr}$. A seasonal pattern for $\mathrm{Hg}$ in precipitation was evident, with increased concentrations and deposition during spring and summer months. Meteorological analysis indicated the highest levels of $\mathrm{Hg}$ in precipitation were associated with regional transport from the south regardless of season, and with transport from the west, southwest and northwest during spring and summer months. Concentrations of ambient vapor phase $\mathrm{Hg}$ were typical of rural locations and consistent across seasons. Ambient particulate $\mathrm{Hg}$ concentrations averaged $11 \mathrm{pg} / \mathrm{m}^{3}$ with highest concentrations during the winter months.
\end{abstract}

Keywords: Mercury, wet deposition, regional transport, particle phase mercury, Lake Champlain

\section{Introduction}

Lake Champlain, located in the northeastern United States on the border between northern New York state, Vermont and Quebec, has been designated as one of the "Great Waters" by the 1990 Clean Air Act Amendments (CAA). The Great Waters program was established in Section 112(m) of the CAA to identify and assess atmospheric deposition of hazardous air pollutants (HAPs) to the Great Lakes, Chesapeake Bay, Lake Champlain and coastal waters. Mercury $(\mathrm{Hg})$ is one of the 189 HAPs identified in this section of the CAA. Requirements of the Great Waters program include: (a) establishing atmospheric deposition stations to monitor deposition of HAPs within the Lake Champlain watershed, (b) determining the role of atmospheric deposition in the pollutant loading for the lake, and (c) investigating the sources of air pollutants deposited in the watershed.

Mercury concentrations exceeding fish consumption advisory limits have been documented for certain sport fish, and elevated levels of $\mathrm{Hg}$ and PCBs have been found in the sediments at many sites within Lake Champlain including those in the deep lake (McIntosh, 1994). This report identified several lake-wide issues for future investigation, including the critical need to better understand how contaminants like $\mathrm{Hg}$ and PCBs are entering Lake Champlain.

Atmospheric deposition has been implicated as a primary source of $\mathrm{Hg}$ to remote lakes in the Great Lakes region (Swain et al., 1992; Fitzgerald et al., 1991). 
Additionally, atmospheric transport of sulfate and acidic precipitation from the major source regions in the Midwest to New York and New England has been demonstrated (NAPAP, 1991). However, measurements of atmospheric $\mathrm{Hg}$ in the Lake Champlain basin have not previously been conducted. Therefore, an assessment of the magnitude and seasonal variation of atmospheric $\mathrm{Hg}$ deposition in the Lake Champlain basin was initiated. The scope of the project included one year of event precipitation collection, as well as collection of vapor and particle phase $\mathrm{Hg}$ in ambient air.

\section{Materials and Methods}

An investigation of atmospheric $\mathrm{Hg}$ concentrations in the Lake Champlain basin began in December 1992 by the University of Michigan Air Quality Laboratory (UMAQL) in collaboration with the Vermont Monitoring Cooperative. Sampling was conducted at the Vermont Monitoring Cooperative air monitoring site at the Proctor Maple Research Center (PMRC) in Underhill Center, VT. Ongoing monitoring at the PMRC site also includes meteorological measurements and routine trace metal measurements as part of the NESCAUM (North East States for Coordinated Air Use Management) air monitoring network.

The PMRC is located within the Lake Champlain basin between the Adirondack mountains in New York State to the west and the Green mountains in Vermont to the east. Underhill Center is approximately $25 \mathrm{~km}$ east of the lake within a forested area on the western side of Mt. Mansfield at approximately $400 \mathrm{~m}$ elevation. No major urban or industrial areas exist within about $200 \mathrm{~km}$.

\subsection{EVENT PRECIPITATION}

Precipitation was collected using an automatic MIC-B collector with a Teflon-coated funnel and glass collection carboy. The protocol used in this study for collection of daily event precipitation for $\mathrm{Hg}$ analysis was developed and proven effective in a four site network in Michigan (Hoyer and Keeler, 1994). Precipitation was collected every morning at 8 A.M. if an event had occurred during the previous 24 hours. If precipitation was occurring at 8 A.M. then the sample was collected the following morning. Samples were poured from the collection carboy into acid-cleaned borosilicate glass bottles and shipped to UMAQL for analysis. A Belfort rain gauge was used to record the amount of precipitation from each event at the site.

Samples were processed immediately upon receipt at the UMAQL in a Class 100 ultra-clean laboratory. An aliquot of sample was poured off for analysis of $\mathrm{pH}$ and anions and the remaining was oxidized to a $1 \% \mathrm{BrCl}$ solution and refrigerated overnight. To determine the amount of $\mathrm{Hg}$ in a precipitation sample the oxidized $\mathrm{Hg}$ was reduced to elemental $\mathrm{Hg}$, bubbled out of solution in a $\mathrm{Hg}$-free nitrogen gas stream, and captured onto a gold-coated sand trap. The $\mathrm{Hg}$ was thermally desorbed from the trap in a $\mathrm{Hg}$-free helium gas stream and then quantified by cold vapor atomic fluorescence spectrometry (CVAFS) (Fitzgerald and Gill, 1979). Aqueous $\mathrm{Hg}$ standards were used to calibrate the instrument during each day of analysis. 
A number of additional analyses were performed on subsets of samples throughout the year. Samples of sufficient volume were analyzed for the operationally-defined reactive $\mathrm{Hg}$ species by acidifying an aliquot of sample to a $1 \% \mathrm{HCl}$ solution. The percent of $\mathrm{Hg}$ in the dissolved phase was determined for several samples by filtering through a $0.4 \mu \mathrm{m}$ pore-size nitrocellulose filter.

\section{$2.2 \mathrm{Hg}$ IN AMBIENT AIR}

Vapor phase $\mathrm{Hg}$ was collected by drawing air at a flow rate of $300 \mathrm{cc} / \mathrm{min}$. into a collection trap containing gold-coated sand. A pre-fired glass-fiber filter was used to remove particles from the air stream prior to reaching the gold sand trap. Samples were collected for 24 hours approximately twice per week: every 6th day on the national network schedule for the U.S. and on Wednesdays to coincide with the NESCAUM network. Collection traps were tested for complete recovery of $\mathrm{Hg}$ vapor between every use. Blanked traps were shipped to the site the week prior to sampling and shipped back for analysis after every two sampling days. Vapor phase $\mathrm{Hg}$ was quantified directly by thermal desorbtion and CVAFS. Mercury vapor standards were used to calibrate the instrument prior to every day of analysis.

Particulate $\mathrm{Hg}$ was collected on a pre-fired glass-fiber filter in an open-face Teflon filter pack at a nominal flow rate of $30 \mathrm{~L} / \mathrm{min}$. (Keeler et al., 1995). Samples were collected for 24 hours on the same every 6th day and Wednesday schedule as vapor phase $\mathrm{Hg}$. After sampling, filters were removed from the filter pack using Teflon-coated forceps, placed in an acid-cleaned petri dish, Teflon-taped and shipped to the UMAQL to be stored in a $-40^{\circ} \mathrm{C}$ freezer until analysis. Prior to analysis, the sample filters were transferred to Teflon vials in the ultra-clean laboratory, extracted using a $10 \%$ nitric and sulfuric acid solution in Teflon vials, sonicated and oxidized with $\mathrm{BrCl}$ (Lamborg et al., 1994). The oxidized $\mathrm{Hg}$ in the extraction solution was reduced to elemental $\mathrm{Hg}$, bubbled out of solution onto a gold sand trap and quantified by CVAFS. The instrument was calibrated during each day of analysis using aqueous $\mathrm{Hg}$ standard solution applied to glass-fiber filters and extracted as described above for sample filters.

\subsection{QUALITY CONTROL AND QUALITY ASSURANCE}

Clean technique was used in handling all samples. All equipment and supplies used in sampling were rigorously acid-cleaned in an 11-day cycle (Hoyer and Keeler, 1994). Sample bottles, gold sand traps and glass-fiber filter containers were Teflon-taped and triple-bagged. Particle-free gloves were worn when handling the samples.

For event precipitation, the funnel and collection carboy were rinsed with ultra-pure water after each sample was collected. A newly acid-cleaned collection carboy was installed every two weeks. As a measure of the sampling blank, the funnel and collection carboy were rinsed after two weeks and analyzed for total $\mathrm{Hg}$ (Hoyer and Keeler, 1994). The average $\mathrm{Hg}$ concentration in 23 precipitation collector blanks was $0.36 \pm 0.2 \mathrm{ng} / \mathrm{L}$.

Field blanks were collected regularly for vapor and particle phase $\mathrm{Hg}$ samples. For both types of samples, field blanks were taken by assembling the sampling equipment and placing it in the sampling box without drawing air through the system. Field blanks 
for vapor phase $\mathrm{Hg}$ averaged $0.02 \mathrm{ng} \mathrm{Hg}$ on the trap, which corresponds to $0.04 \mathrm{ng} / \mathrm{m}^{3}$ for a 24 -hour sample or $2 \%$ of the average vapor phase $\mathrm{Hg}$ concentration. Particle phase $\mathrm{Hg}$ field blanks averaged $7 \mathrm{pg}$ on the filter, which corresponds to $0.2 \mathrm{pg} / \mathrm{m}^{3}$ for a 24 hour sample or $1.5 \%$ of the particulate $\mathrm{Hg}$ typically collected.

For precipitation and particulate samples, a reagent blank was analyzed on each day of analysis. The appropriate amounts of reagents were analyzed to determine the contribution of the reagents to the concentration of $\mathrm{Hg}$ obtained for the sample. All samples were blank corrected using the corresponding reagent blank analyzed that day. The current detection limit for $\mathrm{Hg}$ in precipitation (calculated as three times the standard deviation of reagent blanks) is $0.15 \mathrm{ng} / \mathrm{L}$.

All particulate samples and $50 \%$ of precipitation samples were analyzed in duplicate. Analytical precision calculated from these results were better than $10 \%$ for analysis of $\mathrm{Hg}$ in both precipitation and particulate samples.

An experiment was performed to confirm that $\mathrm{Hg}$ was not being lost from the gold sand traps after sampling, during shipment, or prior to analysis. Gold sand traps were injected with $0.8 \mathrm{ng}$ of elemental $\mathrm{Hg}$ vapor (the average amount of $\mathrm{Hg}$ collected for a 24-hour sample), shipped to the site, stored for three weeks and returned for analysis. Recovery of the injected $\mathrm{Hg}$ from these traps was $100 \%$, indicating no loss of $\mathrm{Hg}$.

A total of 23 precipitation events during 1993 were not analyzed because of insufficient volume. Precipitation events less than $0.08 \mathrm{~cm}$ did not produce sufficient volume for analysis using this collector and carboy system. Overall, insufficient volume samples accounted for less than $2 \%$ of the annual precipitation at Underhill Center and are evenly distributed over the entire year. Eight precipitation events were not analyzed due to collector problems, operator errors or sample bottle breakage. These samples account for less than $8 \%$ of the annual precipitation volume.

\section{Results and Discussion}

\subsection{MERCURY IN PRECIPITATION}

Event precipitation sampling began on December 16, 1992. A total of 125 precipitation samples were analyzed for the time period ending December 22, 1993. The average volume-weighted $\mathrm{Hg}$ concentration for the sampling year was $8.3 \mathrm{ng} / \mathrm{L}$ and the average amount of $\mathrm{Hg}$ deposited with each precipitation event was $0.069 \mu \mathrm{g} / \mathrm{m}^{2}$ (Table I).

TABLE I

Mercury in event precipitation at Underhill Center, VT $(n=125)$

\begin{tabular}{|llccc|}
\hline & Units & Mean & Range & Median \\
\hline Vol. Wt. Average Hg Concentration & $\mathrm{ng} / \mathrm{L}$ & 8.3 & $1.5-26$ & 8.0 \\
Precipitation Amount & $\mathrm{cm}$ & 0.84 & $0.08-4.45$ & 0.5 \\
Wet Deposition of $\mathrm{Hg}$ & $\mu \mathrm{g} / \mathrm{m}^{2}$ & 0.069 & $0.002-0.398$ & 0.039 \\
\hline
\end{tabular}


The results for Underhill Center, VT are similar to the levels of $\mathrm{Hg}$ in precipitation at three sites in Michigan reported by Hoyer et al. (1995) for March 1992 to March 1994. Average $\mathrm{Hg}$ concentration for precipitation events and wet deposition of $\mathrm{Hg}$ at Underhill Center are closest to those for the Pellston site, located in northern Michigan, which had the lowest levels of the three Michigan sites $\left(7.9 \mathrm{ng} / \mathrm{L}, 0.07 \mu \mathrm{g} / \mathrm{m}^{2}\right)$.

The total amount of $\mathrm{Hg}$ deposited by precipitation at the Underhill Center site in 1993 was $9.26 \mu \mathrm{g} / \mathrm{m}^{2} / \mathrm{yr}$. The total annual wet deposition of $\mathrm{Hg}$ for Underhill Center was substantially higher than the average of the two years at Pellston, but similar to Dexter, and significantly less than South Haven, MI (Table II). The amount of precipitation received at Underhill Center during 1993 is considerably larger than the two year averages for the other locations. A comparison of precipitation amounts at Underhill Center for previous years indicates that 1993 was not significantly different from the climatological average. However, when compared to Burlington, VT, located on the eastern shore of Lake Champlain at the widest part of the lake, Underhill Center received approximately 25\% more precipitation during 1993.

This spatial difference in precipitation amounts complicates the calculation of wet deposition of $\mathrm{Hg}$ to the lake surface and drainage basin. Using the annual wet deposition of $\mathrm{Hg}$ at Underhill Center, an estimated $10.5 \mathrm{~kg}$ of $\mathrm{Hg}$ was deposited directly to the surface of Lake Champlain $\left(1129 \mathrm{~km}^{2}\right)$ by precipitation during 1993, and $197.4 \mathrm{~kg}$ of $\mathrm{Hg}$ was deposited to the drainage basin $\left(21,318 \mathrm{~km}^{2}\right)$ of the lake. The actual wet deposition of $\mathrm{Hg}$ to the lake surface is likely to be less than this estimate due to the spatial variation in precipitation amounts.

The total $\mathrm{Hg}$ concentration $(\mathrm{ng} / \mathrm{L})$ and amount of $\mathrm{Hg}$ deposited $\left(\mu \mathrm{g} / \mathrm{m}^{2}\right)$ for each precipitation event from mid-December 1992 through mid-December 1993 are displayed in Figure 1. A seasonal pattern is evident in these results. Mercury concentrations in precipitation are consistently elevated over the annual mean during the period of April through September. Wet deposition of $\mathrm{Hg}$ shows a distinct seasonal trend with several rain events during the months of April through September which had deposition greater than three times the annual mean. Monthly averaged $\mathrm{Hg}$ concentrations were highest in June, while average $\mathrm{Hg}$ deposition peaked in August along with amount of precipitation.

TABLE II

Comparison of annual wet deposition of mercury

\begin{tabular}{|lccc|}
\hline \multicolumn{1}{|c}{ Location } & Reference & $\begin{array}{c}\text { Annual Wet } \\
\text { Deposition } \\
\left(\mu \mathrm{g} / \mathrm{m}^{2} / \mathrm{yr}\right)\end{array}$ & $\begin{array}{c}\text { Precipitation } \\
\text { Amount } \\
(\mathrm{cm} / \mathrm{yr})\end{array}$ \\
\hline Underhill Center, VT & This paper & $9.26^{\mathrm{a}}$ & 111.9 \\
Pellston, MI & Hoyer et al. $(1995)$ & 5.67 & 71.6 \\
Dexter, MI & $"$ & 8.89 & 87.2 \\
South Haven, MI & " & 11.06 & 102.7 \\
\hline
\end{tabular}

a Insufficient volume samples and missed precipitation events included by using amount of precipitation from Belfort gauge and average concentration for month. 

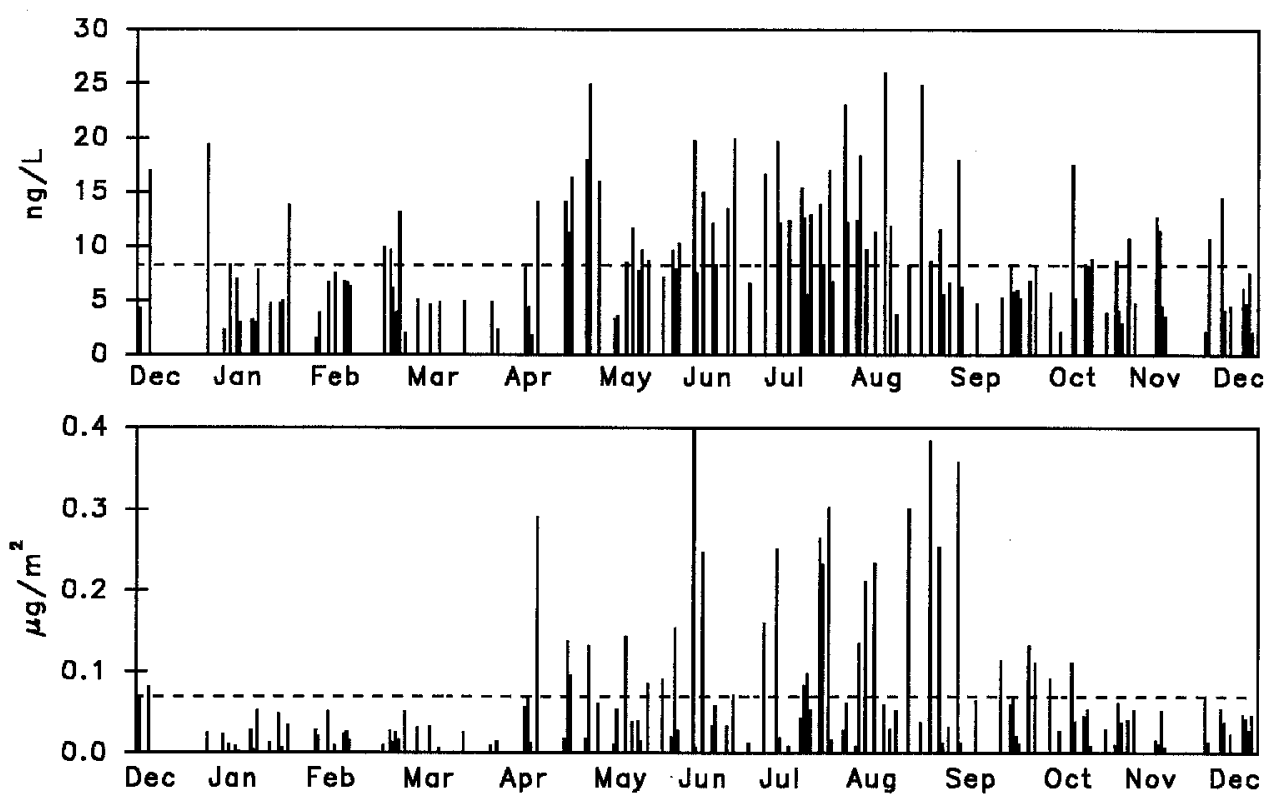

Fig. 1. Hg in event precipitation at Underhill Center, VT during 1993. Top graph is Hg concentration in $\mathrm{ng} / \mathrm{L}$, bottom graph is wet deposition of $\mathrm{Hg}$ in $\mu \mathrm{g} / \mathrm{m}^{2}(-\ldots=$ annual mean).

Seasonal averages of $\mathrm{Hg}$ in precipitation further illustrate this trend (Table III). Concentrations of $\mathrm{Hg}$ in precipitation were significantly higher during the spring and summer compared to the winter and autumn. Of the 20 highest $\mathrm{Hg}$ concentration events, $80 \%$ occurred during the spring and summer. The amount of $\mathrm{Hg}$ deposited to this site in precipitation was lowest on average during the winter, increased dramatically during the spring, reached a peak during the summer and dropped significantly during autumn.

\section{TABLE III}

Seasonal $\mathrm{Hg}$ averages and total deposition for precipitation at Underhill Center, VT during 1993

\begin{tabular}{|lcccccc|}
\hline Season & $\mathrm{n}$ & $\begin{array}{c}\text { Vol. Wt. } \\
\text { Average } \\
\text { Hg Conc. } \\
(\mathrm{ng} / \mathrm{L})\end{array}$ & $\begin{array}{c}\text { Average } \\
\text { Wet } \\
\text { Deposition } \\
\left(\mu \mathrm{g} / \mathrm{m}^{2}\right)\end{array}$ & $\begin{array}{c}\text { Average } \\
\text { Precip. } \\
\text { Amount } \\
(\mathrm{cm})\end{array}$ & $\begin{array}{c}\text { Season } \\
\text { Wet } \\
\text { Deposition } \\
\left(\mu \mathrm{g} / \mathrm{m}^{2}\right)\end{array}$ & $\begin{array}{c}\text { Season } \\
\text { Precip. } \\
\text { Amount } \\
(\mathrm{cm})\end{array}$ \\
\hline Winter & 26 & 4.4 & 0.025 & 0.56 & 0.72 & 16.1 \\
Spring & 29 & 9.9 & 0.080 & 0.81 & 2.59 & 26.6 \\
Summer & 35 & 11.0 & 0.115 & 1.04 & 4.32 & 38.8 \\
Autumn & 31 & 6.2 & 0.055 & 0.88 & 1.54 & 27.6 \\
\hline
\end{tabular}


The seasonal pattern for wet deposition of $\mathrm{Hg}$ is not solely due to seasonal differences in precipitation amounts. Higher $\mathrm{Hg}$ concentrations and larger amounts of rain combine to produce the summer wet deposition peak. The average amount of precipitation per event during the winter months is about half that for the summer months, while the average deposition of $\mathrm{Hg}$ per event during winter is only $20 \%$ of that for summer. Wet deposition of $\mathrm{Hg}$ for each season is also displayed in Table III. The spring and summer months account for $60 \%$ of the annual precipitation. However, $75 \%$ of the annual wet deposition of $\mathrm{Hg}$ at this site occurs during these months.

The operationally-defined reactive $\mathrm{Hg}$ species was quantified for a total of 40 precipitation samples during the period from January through July 1993 (Table IV). The concentration of reactive $\mathrm{Hg}$ species in precipitation was generally low $(<3 \mathrm{ng} / \mathrm{L})$. The average percent of total $\mathrm{Hg}$ as this reactive species was $15 \%$, but was observed as high as $39 \%$. Concentrations of reactive and total $\mathrm{Hg}$ were significantly correlated $(\mathrm{r}=0.47$, $\mathrm{p}<0.01)$. However, the percent reactive $\mathrm{Hg}$ was negatively correlated with total $\mathrm{Hg}$ concentration $(\mathrm{r}=-0.57, \mathrm{p}<0.0001)$. The reactive $\mathrm{Hg}$ concentration increased and the percent reactive decreased as total $\mathrm{Hg}$ concentration increased, indicating that reactive $\mathrm{Hg}$ levels were relatively constant compared to the total $\mathrm{Hg}$ in precipitation for this site.

Filtration of precipitation samples with sufficient volume was performed for 5 samples during the spring and for 11 samples during the autumn using a $0.4 \mu \mathrm{m}$ pore size filter. The percent of total $\mathrm{Hg}$ in the dissolved phase was greater than $50 \%$ on average, and ranged up to nearly $90 \%$ (Table IV).

Major ions were quantified for the precipitation samples. Significant correlations between ion and $\mathrm{Hg}$ concentrations in precipitation were observed (Table V). The wet deposition of sulfate, nitrate, chloride and acidity correlated strongly with the wet deposition of $\mathrm{Hg}$ as well. Also, the concentration of reactive $\mathrm{Hg}$ species showed a significant correlation with chloride ion concentration $(r=0.54, p<0.001, n=40)$.

\subsection{MERCURY IN AMBIENT AIR}

A total of 91 vapor phase and 103 particle phase $\mathrm{Hg}$ samples were collected during 1993 (Table VI). The average vapor phase $\mathrm{Hg}$ concentration was $2.0 \mathrm{ng} / \mathrm{m}^{3}$. Similar levels for vapor phase $\mathrm{Hg}$ have been observed in other rural locations in the Great Lakes region (Lamborg et al., 1993), and in New York state (Olmez, 1994).

TABLE IV

Reactive and dissolved $(<0.4 \mu \mathrm{m}) \mathrm{Hg}$ in precipitation at Underhill Center, VT

\begin{tabular}{|lcccc|}
\hline & $\mathrm{n}$ & Mean & Range & Median \\
\hline Reactive Hg (ng/L) & 40 & 1.0 & $0.15-2.99$ & 0.8 \\
Percent Reactive Hg & 40 & $15 \%$ & $2-39 \%$ & $14 \%$ \\
& & & & \\
Dissolved Hg (ng/L) & 16 & 5.1 & $2.0-12.5$ & 3.7 \\
Percent Dissolved Hg & 16 & $66 \%$ & $38-89 \%$ & $68 \%$ \\
\hline
\end{tabular}




\section{TABLE V}

Significant correlations for $\mathrm{Hg}$ and ions in precipitation at Underhill Center, VT $\mathrm{p}<0.01(\mathrm{n}=112)$

\begin{tabular}{|ccc|}
\hline Ion & $\begin{array}{c}\text { Concentration } \\
\mathrm{r}=\end{array}$ & $\begin{array}{c}\text { Wet Deposition } \\
\mathrm{r}=\end{array}$ \\
\hline $\mathrm{NO}_{3}^{-}$ & 0.25 & 0.73 \\
$\mathrm{SO}_{4}^{-2}$ & 0.46 & 0.88 \\
$\mathrm{Cl}^{-}$ & 0.30 & 0.48 \\
$\mathrm{H}^{+}$ & 0.39 & 0.82 \\
\hline
\end{tabular}

Levels of vapor phase $\mathrm{Hg}$ were fairly consistent throughout the sampling year at Underhill Center. Only six samples had elevated vapor phase $\mathrm{Hg}$ concentrations (greater than 1 std. dev. above the annual mean). Three of these samples occurred during the winter, however, the three highest vapor phase $\mathrm{Hg}$ measurements were in June and July.

For particle phase $\mathrm{Hg}$, the annual average concentration was $11 \mathrm{pg} / \mathrm{m}^{3}$. A seasonal trend was observed, with elevated particulate $\mathrm{Hg}$ concentrations during the winter months, especially in February when all samples were above the annual average (Figure 2). Increasing concentrations in November and December of 1993 provide further support for a seasonal influence on particulate $\mathrm{Hg}$ concentrations at this site. A similar increase in the concentration of other metals such as As and Se measured at Underhill Center (NESCAUM data) during the winter months was also observed.

Seasonally averaged particulate $\mathrm{Hg}$ concentrations further illustrate this trend. The average for the winter months $\left(16 \mathrm{pg} / \mathrm{m}^{3}\right)$ is significantly greater than the annual mean concentration $\left(11 \mathrm{pg} / \mathrm{m}^{3}\right)$, while the averages for the other seasons $\left(9-10 \mathrm{pg} / \mathrm{m}^{3}\right)$ are similar to the annual average.

\subsection{CONCURRENT PRECIPITATION AND AMBIENT RESULTS}

One of the unique aspects of this project is that concurrent measurements of $\mathrm{Hg}$ in precipitation and ambient air were obtained. Simple correlations were calculated between ambient and precipitation concentrations for the sampling days when precipitation occurred during ambient measurements. Some interesting correlations were observed. Ambient particulate $\mathrm{Hg}$ was correlated with reactive $\mathrm{Hg}$ in precipitation $(\mathrm{r}=0.654, \mathrm{p}<0.02, \mathrm{n}=13)$. A significant correlation was also found between vapor phase $\mathrm{Hg}$ and wet deposition of $\mathrm{Hg}(\mathrm{r}=0.471, \mathrm{p}<0.01, \mathrm{n}=33)$.

TABLE VI

Ambient Hg Concentrations at Underhill Center, VT during 1993

\begin{tabular}{|lcccc|}
\hline & $\mathrm{n}$ & Mean & Range & Median \\
\hline Vapor phase $\mathrm{Hg}\left(\mathrm{ng} / \mathrm{m}^{3}\right)$ & 91 & 2.0 & $1.2-4.2$ & 1.9 \\
Particle phase $\mathrm{Hg}\left(\mathrm{pg} / \mathrm{m}^{3}\right)$ & 103 & 11 & $1-43$ & 10 \\
\hline
\end{tabular}




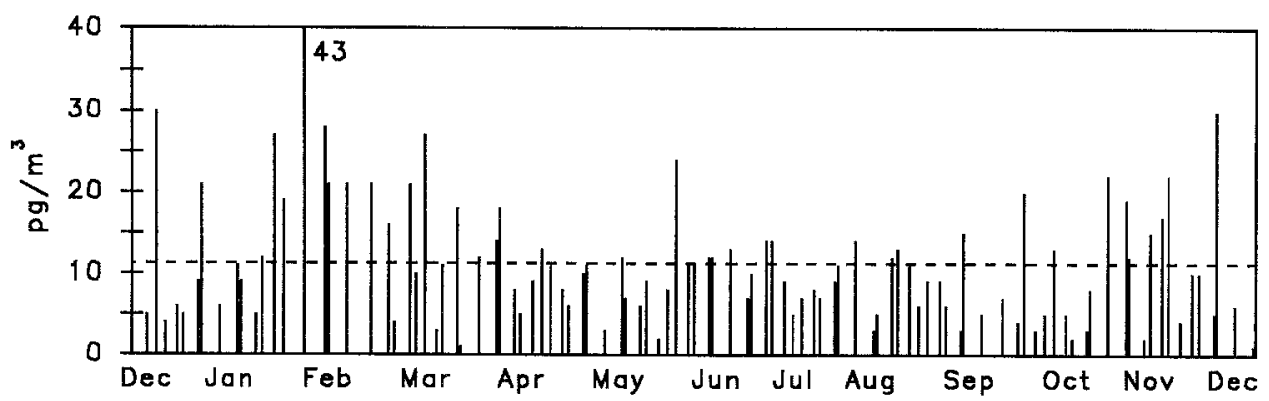

Fig. 2. Ambient particulate $\mathrm{Hg}$ concentrations in $\mathrm{pg} / \mathrm{m}^{3}$ at Underhill Center, VT during 1993 (--- = annual mean).

Averages calculated for these sampling days did not differ significantly from the annual means for $\mathrm{Hg}$ in precipitation or for vapor phase $\mathrm{Hg}$. However, the particulate average was $\sim 20 \%$ lower than the annual mean. This may be due to upwind removal of ambient particulate matter by precipitation or simply the result of air mass changes associated with the passage of frontal systems.

\subsection{METEOROLOGICAL ANALYSIS}

Meteorological influences on atmospheric $\mathrm{Hg}$ at Underhill Center were also investigated. The Hybrid Single-Particle Lagrangian Integrated Trajectories Model (HySPLIT) was used with 1993 meteorological input data from the National Meteorological Center's Nested Grid Model (NGM) for the continental US (90 to $180 \mathrm{~km}$ every 1 to $2 \mathrm{hr}$ ) to plot iso-sigma backward trajectories (Draxler, 1992). Each trajectory plot displays the most probable path of the air mass that arrived at the site on the day and hour specified.

Trajectories for every precipitation event at Underhill Center during 1993 were analyzed and classified by region. Trajectories from southern New England and the eastern half of the mid-Atlantic states were classified as transport from the south. Western New York State and Pennsylvania, and eastern Ohio were considered the southwest region. The upper Midwest and southern Ontario were classified as the west region and the rest of Ontario and western Quebec was considered the northwest region.

Preliminary analysis of these trajectories showed that for the 20 precipitation events with the highest $\mathrm{Hg}$ concentrations, $30 \%$ were associated with regional transport from the south, $30 \%$ from the west and the remaining events were split between the southwest and northwest. Precipitation events with the lowest $\mathrm{Hg}$ concentrations generally involved transport with an easterly component.

The elevated $\mathrm{Hg}$ concentrations in precipitation associated with transport from the south were distributed throughout the sampling year, indicating this source region is consistently influencing $\mathrm{Hg}$ concentrations in precipitation at Underhill Center. However, the 20 precipitation events with the highest concentrations in precipitation that were associated with transport from the west, southwest and northwest were seasonally dependent. Elevated $\mathrm{Hg}$ concentrations in precipitation associated with transport from the west occurred only during the summer months. High $\mathrm{Hg}$ concentrations associated with transport from the northwest occurred only during the spring, and with transport 
from the southwest during both spring and summer. Also interesting to note is that of all the precipitation events during the summer, none were associated with transport from the east, northeast or southeast which typically brought low $\mathrm{Hg}$ concentrations in precipitation during the other seasons.

\section{Conclusions}

Results reported from this first year of atmospheric $\mathrm{Hg}$ sampling at Underhill Center, VT indicate that wet deposition of $\mathrm{Hg}$ is significant at this site, and therefore, atmospheric deposition is an important source of $\mathrm{Hg}$ to the Lake Champlain basin. The seasonal variation observed for $\mathrm{Hg}$ in precipitation with higher concentrations in the spring and summer may be influenced by several factors including meteorology, regional transport patterns, source strengths, cloud processes or other atmospheric constituents during the different seasons. Further investigations of how these factors affect atmospheric $\mathrm{Hg}$ concentrations are clearly needed.

The significant relationship observed between $\mathrm{Hg}$ and major ions in precipitation at Underhill Center may imply a degree of similarity in the sources or mechanisms for atmospheric transport of $\mathrm{Hg}$ with that of sulfate and the formation of acidic precipitation.

The observed correlation between the operationally-defined reactive $\mathrm{Hg}$ species and $\mathrm{Cl}^{-}$in precipitation provides support for the speculation that this species may be $\mathrm{HgCl}_{2}$. Also, the correlation observed between ambient particulate $\mathrm{Hg}$ and reactive $\mathrm{Hg}$ species in precipitation on days when ambient measurements were conducted and precipitation occurred, implies that this species may be associated with particles.

\section{Acknowledgments}

We would like to acknowledge the efforts of those involved in sample collection and analysis who contributed greatly to the quality of the data, especially Joanne Cummings and Carl Waite (PRMC); Anne Rea, Ann Krueger, Lisa Cleckner, Tim Dvonch, Tamar Krantz and Elizabeth Esseks (UMAQL). In addition, we thank Kristie Mukherjee for her assistance with data processing. This research was sponsored by the Cooperative Institute of Limnology and Ecosystems Research (CILER) under cooperative agreements from the Environmental Research Laboratory (ERL), National Oceanographic and Atmospheric Administration (NOAA), U.S. Department of Commerce under Cooperative Agreement No. NA90RAH00079.

\section{References}

Draxler, R. R.: 1992, NOAA Technical Memorandum ERL ARL-195, US Dept. of Commerce.

Fitzgerald, W. F., Mason, R. P., Vandal, G. M.: 1991, Water, Air and Soil Pollution, 56, 745.

Fitzgerald, W. F. and Gill, G. A.:1979, Anal. Chem., 51, 1714.

Hoyer, M. E. and Keeler, G. J.: 1994, submitted to Environ. Sci. Technol.

Hoyer, M. E., Burke, J. M., Keeler, G. J.: this volume.

Keeler, G. J., Glinsorn, G. and Pirrone, N.: this volume.

Lamborg, C. H., Hoyer, M. E., Keeler, G.J., Olmez, I. and Huang, X.: 1994, In: Mercury as a Global PollutantToward Integration and Synthesis. Watras, C. J. and Huckabee, J. Eds. In press.

Lamborg, C. H., Fitzgerald, W. F., Vandal, G. M., Rolfhus, K. R.: 1993, In: Proceedings of the 9th Intl. Conference on Heavy Metals in the Environment, Allan, R. J. and Nriagu, J. O. Eds., CEP Consultants Ltd., Edinburgh.

McIntosh. A.: 1994, Lake Champlain Sediments Toxics Assessment Program, An Assessment of Sediment Associated Contaminants in Lake Champlain-Phase 1, UVM School of Natural Resources.

National Acid Precipitation Assessment Program (NAPAP): 1991, Acidic Deposition: State of Science and Technology Vol. 1, Emissions, Atmospheric Processes and Deposition, Report 8.

Olmez, I.: 1994, personal communication.

Swain, E. B., Engstrom, D. R., Brigham, M. E., Henning, T. A. and Brezonik, P. L.: 1992, Science $257,784$. 